\title{
Laccase-catalyzed Decolorization of the Synthetic Azo-dye Diamond Black PV 200 and of some Structurally Related Derivatives
}

\author{
ANDREAS KANDELBAUER ${ }^{\mathrm{a}, \mathrm{b} *}$, ANGELIKA ERLACHER $^{\mathrm{b}}$, ARTUR CAVACO-PAULO $^{\mathrm{c}}$ and GEORG M. \\ GUEBITZ $^{\mathrm{b} *}$ \\ ${ }^{a}$ Department of Applied Research, Funder Industrie GesmbH, Klagenfurterstrasse 87-89, A-9300 St. Veit an der Glan, Austria; ${ }^{b}$ Department of \\ Environmental Biotechnology, University of Technology Graz, Petersgasse 12, A-8010 Graz, Austria; ${ }^{c}$ Department of Textile Engineering, University \\ of Minho, 4800 Guimaraes, Portugal
}

The kinetics of laccase-catalyzed transformation of the azo-dye Diamond Black PV 200 (CI Mordant Black 9) and various related synthesized derivatives were analyzed for dependence on $\mathrm{pH}$ and substrate structure. The reaction mixture of Diamond Black PV 200 was analyzed by HPLC/MS-MS and it was shown that upon laccase oxidation, reactive chinoid fragments of lower molecular weight were formed. These may further oligomerize as indicated by the appearance of a number of compounds with increased molecular weight. The $\mathrm{pH}$ optimum for the decolorization was pH 5 for Diamond Black PV 200 which did not change significantly when the substitution pattern of its basic structure was varied. Biodegradability, however, was strongly dependent on the structure of the dyes.

Keywords: Laccase; Azo-dyes; Bioremediation; Enzyme Kinetics; Dye Transformation; Substrate Specificity

\section{INTRODUCTION}

Excess dyestuff in process water is highly undesirable because of environmental concerns. Due to their chemical structure, dyes are highly recalcitrant and often toxic or can lead to toxic transformation products when released into the environment. Therefore, their complete mineralisation is desired. Various physical and chemical methods for the elimination of dyestuff have been developed during the past decades. However, they all inevitably cause high consumption of chemicals and energy (Slokar and Le Marechal, 1998; Robinson et al., 2001).

Biotechnological approaches are gaining increasing interest in the textile industry (Cavaco-Paulo and Gübitz, 2004). Bioremediation techniques for textile wastewater are currently evolving as promising sustainable alternatives (Binkley and Kandelbauer, 2003; Kandelbauer and Gübitz, in press) and a huge number of microbial systems, both, aerobic and anaerobic have been described in this context (McMullan et al., 2001; Stolz 2001). Fungi, with their ligninolytic enzyme systems are also being applied in the biological decolorization of textile dyestuff (Martins et al., 2003; Kapdan and Kargi, 2002; Fu and Viraraghavan 2001). Besides adsorption onto fungal mycelia and merely removing dyestuff physically from the effluent (Sumathi and Manju, 2000), oxidative biodegradation takes place upon action of enzymes such as peroxidases and laccases (Wesenberg et al. 2003).

Laccase ( $p$-diphenol oxidase, EC1.10.3.2) catalyzes the oxidation of phenolic compounds and aromatic amines and accepts a broad range of substrates (Claus, 2004; Thurston, 1994). The number of substrates can further be extended by using laccase in combination with mediators (Reyes et al., 1999). Laccase requires only molecular oxygen as a cosubstrate which is concomittantly reduced to water. This makes it very interesting for use in enzyme-based bioreactors (Kandelbauer et al ., 2004; Peralta-Zamora et al., 2003).

Laccases have been used over the past two decades for the elimination of aromatic compounds in various types of effluents (Bollag et al., 1988; Bajpai et al., 1993; Majcherczyk et al., 1998; D'Annibale et al., 1999). Until now, laccases from many different fungi such as Trametes versicolor (Wong and Yu, 1999), Trametes hirsuta (Abadulla et al., 2000;

\footnotetext{
* Corresponding authors. Tel.: + 434212494 374. E-mail: andreas.kandelbauer@funder.at (A.K.); Tel.: + 433168738312. E-mail: guebitz@ima.tu-graz.ac.at (G.G.)
} 
Campos et al., 2001), Trametes modesta (Nyanhongo et al., 2002), Sclerotium rolfsii (Campos et al ., 2001), Irpex lacteus, Pleurotus ostreatus (Novotny et al., 2001), Pycnoporus cinnabarinus (Schliephake et al., 2000), Pyricularia oryzae (Chivukula and Renganathan, 1995) or Phlebia tremellosa (Kirby et al., 2000) have been described for the decolorization of a wide structural variety of dyes.

However, although a large number of structurally diverse dyes can be successfully oxidized by laccases, decolorizations take place at different rates and to different extents and many dyes are not degraded at all (Kandelbauer et al., 2004). Little information is available concerning the substrate specifities of laccases. One key parameter for the description of the structure-biodegradability relationship has been identified as the redox-potential of the substrates (Xu, 1996; Xu et al., 2000). Although chemometrical methods have been employed in order to classify dyes according to their biodegradability (Suzuki et al., 2001), no generally valid models have been deduced so far. However, gaining insights in the degradation pathways of dyes and the structural requirements for biodegradability is important (Gübitz et al., in press) in order to optimize potential bioremediation systems for industrial textile process water treatment.

In order to extend current knowledge about structure-reactivity relationships in laccase-catalyzed azo-dye decolorization, a number of structurally related model azo-dyes have been synthesized and their kinetics with respect to laccase-catalyzed oxidation was analyzed. Their common structural feature was based on the commercial azo-dye Diamond Black PV 200 (CI Mordant Black 9, IV) which was shown to be readily biodegradable using laccase (Kandelbauer et al., 2004). Reaction products of enzymatic Diamond Black PV 200 oxidation were analyzed in more detail using HPLC/MS.

\section{MATERIALS AND METHODS}

\section{Chemicals}

Diamond Black PV 200 (CI Mordant Black 9, IV) was kindly donated by DyeStar (Frankfurt, Germany) and was used for screening experiments without any further purification. For kinetic measurements the dye was purified by silica gel column chromatography. The diazo components 4-aminonaphthaline sulfonic acid, 3-aminobenzene sulfonic acid, 3-amino-4-hydroxybenzene sulfonic acid, 3-amino-4hydroxy-5-nitrobenzene sulfonic acid and coupling compound 1,5-dihydroxynaphthaline (analytical grade) were from Sigma (St. Louis, MO). 2,2-azinobis-(3-ethylbenzothiazoline-6-disulfonic acid) diammonium salt (ABTS), citric acid, sodium azide, and the HPLC solvents methanol and water were also from Sigma.

\section{Biocatalyst and Enzyme Activity}

Laccase production by Trametes modesta was essentially as already described (Nyanhongo et al., 2002). After ten days of cultivation on PDA petri plates, mycelial mats $\left(1 \mathrm{~cm}^{2}\right)$ were cut and used to prepare liquid precultures for subsequent inoculation of larger scale production vessels. The basal media consisted of glucose $\left(1 \mathrm{~g} \mathrm{~L}^{-1}\right)$, yeast extract $(1.5 \mathrm{~g}$ $\left.\mathrm{L}^{-1}\right), \mathrm{KH}_{2} \mathrm{PO}_{4}\left(2.5 \mathrm{~g} \mathrm{~L}^{-1}\right),\left(\mathrm{NH}_{4}\right)_{2} \mathrm{SO}_{4}\left(1 \mathrm{~g} \mathrm{~L}^{-1}\right)$, $\mathrm{Na}_{2} \mathrm{HPO}_{4}\left(2.5 \mathrm{~g} \mathrm{~L}^{-1}\right), \mathrm{MgSO}_{4} \cdot 7 \mathrm{H}_{2} \mathrm{O}\left(4 \mathrm{~g} \mathrm{~L}^{-1}\right)$, and trace elements. Supplements of copper chloride (100 $\mathrm{mg} \mathrm{L}^{-1}$ ) and wheat bran flakes $\left(20 \mathrm{~g} \mathrm{~L}^{-1}\right)$ were added as laccase inducers (Kandelbauer et al., 2003; Pickard et al., 1999). The $\mathrm{pH}$ was adjusted to $\mathrm{pH} 3.7$ prior to autoclaving. After two days of fermentation in an aerated stirred tank reactor, the laccase was harvested and further processed as described in Kandelbauer et al. (2003). Enzyme activity of the dialyzed biocatalyst solutions was assayed using the laccase-catalyzed oxidation of ABTS (molar extinction coefficient $\varepsilon_{M}=43.2$ $\mathrm{mM}^{-1} \mathrm{~cm}^{-1}$ ) following the increase in absorbance at $420 \mathrm{~nm}$.

\section{Preparation of Model Dyes}

The structurally related model azo-dyes 1,5dihydroxy-2-naphthylazo-3'-sulfonic acid (I), 1,5dihydroxy-2-phenylazo- $4^{\prime}$-sulfonic acid (II), 1,5-dihydroxy-2-phenylazo-3'-sulfonic acid (III), and 1,5-dihydroxy-2-(2'-hydroxy-3'-nitro)phenylazo-5'sulfonic acid (V) (see Fig. 1) were prepared as follows. $12.5 \mathrm{mmol}$ of the diazo components were dissolved in three equivalents of $16 \%$ hydrochloric acid. After cooling the solution to about $-10^{\circ} \mathrm{C}$ using a salt/ice mixture (1:3), $5 \mathrm{~mL}$ of $2.5 \mathrm{M}$ sodium nitrite solution were slowly added under stirring. The diazotated product was subsequently added to a stirred basic dispersion of the coupling component 1,5-dihydroxynaphthaline in $25 \mathrm{~mL}$ of $2 \mathrm{M}$ sodium hydroxide solution. The precipitated dye was recrystallized and dried.

\section{Purity of Azo-dyes}

Concentrations of the azo compounds present in the synthesized dye preparations, as well as the purified DBPV were confirmed via redox titration of known amounts of dye with sodium dithionite under anaerobic conditions according to the modified method of Bechtold et al. (2001). The decrease in absorbance at the absorbance maximum $\lambda_{\max }$ of the respective dye was followed spectrophotometrically. 
<smiles>O=S(=O)(O)c1ccc(COS(=O)(=O)c2cccc(N=Nc3c(S(=O)(=O)O)ccc(N=Nc4ccc5c(O)cccc5c4O)c3N=Nc3ccc4c(O)cccc4c3O)c2)cc1</smiles>

FIGURE 1 Structures of the model dyes used in this study. (I) 4sulfophenyl-DB, (II) 3-sulfophenyl-DB, (III) naphthyl-DB, (IV) DBPV, (V) nitro-DB.

The initial decay rate was determined by linear regression and extrapolated for zero absorbance. Sodium dithionite was calibrated with iodine/potassium iodide standard solutions.

\section{HPLC/MS Analysis}

Dyes and their transformation products were separated in a Dionex HPLC system (Dionex Corporation, Sunnyhill, Calif.) consisting of a P580 pump, an ASI-100 automated sample injector, and a PDA-100 photodiode array UV/Vis detector. Separation was performed through a Hypersil ODS 5- $\mu \mathrm{m}$ $(250 \times 4 \mathrm{~mm}$ [inside diameter]) column. The following operating conditions were used for all analyses: injection volume, $20 \mu \mathrm{L}$; the mobile phase was methanol/citrate buffer $\mathrm{pH} 7.5$ (55/45); flow rate was $0.9 \mathrm{~mL} \mathrm{~min}^{-1}$. The HPLC was connected to a SL ion trap mass spectrometer (1100 Series LC/MSD Trap, Agilent, Waldbronn, Germany) equipped with an electrospray ionization source. The spectra were recorded in negative ionization mode. Full-scan spectra were collected from 100 to $800 \mathrm{~m} / \mathrm{z}$, with a capillary temperature of $350^{\circ} \mathrm{C}$. The nebulizer was set to 483 kpascal, the dry gas was set to $12.00 \mathrm{~L} \mathrm{~min}^{-1}$, and the HV capillary was set to $3,000 \mathrm{~V}$. Extracted ion chromatograms were obtained by selecting ions e.g. $[\mathrm{M}-\mathrm{H}]^{-}$at $359 \mathrm{~m} / z$ (for Diamond Black PV 200, IV). MS-MS fragmentation patterns of interesting ions were recorded and interpreted.

\section{Diamond Black PV 200 Transformation}

For the analysis of the transformation products of the parent dye, Diamond Black PV 200, $0.56 \mathrm{~g} \mathrm{~L}^{-1}$ of commercial IV were dissolved in $20 \mathrm{~mL} 100 \mathrm{mM}$ citrate buffer at $\mathrm{pH}$ 5.0. Dye transformation was started at room temperature by addition of $100 \mathrm{nkat}$ $\mathrm{mL}^{-1}$ laccase. After 3 hours, $200 \mu \mathrm{L}$ of $0.1 \mathrm{mM}$ sodium azide solution were added to the reaction mixture in order to stop the reaction by enzyme inhibition. The solutions were analyzed by HPLC/ MS as described above.

\section{Dye Decolorization Kinetics}

The kinetic profiles for all azo-dyes (I to V) were determined using dye concentrations from 0.01 to $1.5 \mathrm{mM}$ in $25 \mathrm{~mL}$ of total reaction volume. The $\mathrm{pH}$ optima were determined using citrate buffer at $\mathrm{pHs}$ varying from $\mathrm{pH} 3$ and $\mathrm{pH} 7$ as the reaction medium. All decolorizations were carried out at room temperature $\left(25^{\circ} \mathrm{C}\right)$.

After taking a zero sample, decolorization was started by the addition of laccase. Laccase concentrations were chosen appropriately and the calculated rates were then normalized to the amount of enzyme used. Samples $(100 \mu \mathrm{L})$ were withdrawn at regular time intervals, the first five samples being withdrawn every 30 seconds with these intervals being increased as the reaction proceeded from every minute to every five, ten and fifteen minutes until the reaction was finished. The samples were transferred to HPLC vials containing $100 \mu \mathrm{L}$ of $0.1 \mathrm{mM}$ sodium azide in $300 \mu \mathrm{L}$ citrate buffer which immediately caused the reaction to stop by inhibition of the enzyme. The samples were subsequently analyzed by HPLC. For UV/Vis spectroscopic detection, the dye absorbance maxima were used as given in Table II. The initial rates were determined from the decrease in the chromatographic peaks by linear 
TABLE I HPLC/MS analysis of the laccase-catalyzed oxidation of Diamond Black PV

\begin{tabular}{rcccl}
\hline & $R_{\mathrm{t}}(\min )$ & $M_{\mathrm{W}}(\mathrm{m} / \mathrm{z})$ & Area $(\%)$ & \multicolumn{1}{c}{ Assignment } \\
\hline$(1)$ & 1.18 & 191 & 22.0 & Citric acid \\
$(2)$ & 1.67 & 186 & 5.1 & 3,4-Dioxo-benzene sulfonic acid, structure see Fig. 2, VII \\
$(3)$ & 5.40 & 359 & 3.3 & Diamond Black PV 200 \\
$(4)$ & 5.70 & 388 & 26.3 & radical combination product, possible structure see Fig. 2, VI \\
$(5)$ & 5.99 & 401 & 33.9 & Acetylated Diamond Black PV \\
$(6)$ & 6.32 & 468 & 3.8 & Not identified \\
$(7)$ & 6.53 & 452 & 2.6 & Not identified \\
$(8)$ & 7.23 & 715 & 0.5 & Not identified \\
$(9)$ & 7.26 & 717 & 1.0 & Not identified \\
$(10)$ & 7.50 & 726 & 1.4 & Not identified \\
\hline
\end{tabular}

$R_{\mathrm{t}}$, retention time; $M_{\mathrm{W}}$, molecular weight; $m / z$, mass-to-charge ratio; area, relative peak area from the chromatograms.

regression using the dye conversion data within the first 5 to 15 minutes of the reaction. The retention times for the analyzed dyes are given in Table I. $V_{\max }^{\mathrm{app}}, K_{\mathrm{M}}^{\mathrm{app}}$ and apparent inhibition constants $K_{\mathrm{I}}^{\mathrm{app}}$ were calculated from the initial rates at different dye concentrations by non-linear regression using the computer programm Origin. Specificity constants $k_{\text {cat, dye }}$ were obtained as the ratio $V_{\max }^{\mathrm{app}} / K_{\mathrm{M}}^{\mathrm{app}}$.

\section{RESULTS}

\section{Transformation of Diamond Black PV 200}

Initially, a commercial preparation of Diamond Black PV 200 (IV) was subjected to laccase-catalyzed oxidation at $\mathrm{pH}$ 5. The dye was readily decolorized, as illustrated by the spectral time course of the visspectra depicted in Fig. 3. Although the absorbance maximum at $530 \mathrm{~nm}$ had decreased to about $10 \%$ of the original signal after three hours, the reaction mixture was not completely decolorized but still had a brownish hue. In order to clarify the nature of the formed coloured products HPLC/MS-MS analysis of the final reaction mixture was performed.

\section{Mass spectral analysis}

HPLC analysis of the reaction mixture indicated the presence of at least nine products $\left(R_{\mathrm{t}}\right.$ of $1.18,1.67$, $5.40,5.70,5.99,6.32,6.53,7.23,7.26$, and $7.50 \mathrm{~min}$ ).

The buffer compound citric acid was found to elute first $\left(R_{\mathrm{t}}=1.18 \mathrm{~min}\right)$ and was positively identified $\left([\mathrm{M}-\mathrm{H}]^{-}=191 ;[2 \mathrm{M}+\mathrm{Na}+2 \mathrm{H}]^{-}=405\right)$.

The compound with $R_{\mathrm{t}}$ of 5.40 was positively identified as the undegraded Diamond Black PV by its mass spectrum $(359 \mathrm{~m} / z)$. Comparison with the fragmentation pattern of the untreated dye showed the same three major signals: $279 \mathrm{~m} / z$ (loss of sulfonate group), $186 \mathrm{~m} / z$ (loss of sulfonated phenyl of mass $171 ; 171 \mathrm{~m} / z$ (complementary fragment).

The compound eluted after 5.99 minutes was identified as the acetylated Diamond Black derivative $(401 \mathrm{~m} / z)$ as indicated by the additional splitting of $43 \mathrm{~m} / z$ fragments but otherwise very similar mass spectrum compared to the Diamond
Black PV 200 fragmentation pattern. The same peak was also present in the original dye chromatogram. Upon laccase treatment, no decrease in the integrated peak area at $R_{\mathrm{t}} 5.99$ was detected indicating that the acetylated dye is not attacked by the laccase. We assume that the dye was acetylated in the naphtylring since the MS-MS showed the loss of a $171 \mathrm{~m} / z$ fragment both from the signal at $401 \mathrm{~m} / \mathrm{z}$ and at $358 \mathrm{~m} / z$. The substitution was most likely at the ortho-hydroxy group next to the azobond in order to exhibit the inhibitory effect towards enzymatic oxidation.

Mass spectral analysis of the chromatographic peak with $R_{\mathrm{t}}=3.78$ revealed a compound of smaller molecular weight $(187 \mathrm{~m} / z)$ than the dye. One likely structure is given in Fig. 2 (VII).

The main Diamond Black transformation product was found at $R_{\mathrm{t}} 5.70$ and had a molecular mass of $388 \mathrm{~m} / z$. The secondary mass spectrum (focused on $388 \mathrm{~m} / z$ ) yielded three main peaks at $388 \mathrm{~m} / \mathrm{z}, 308$, 280 with decreasing signal intensity, indicating that

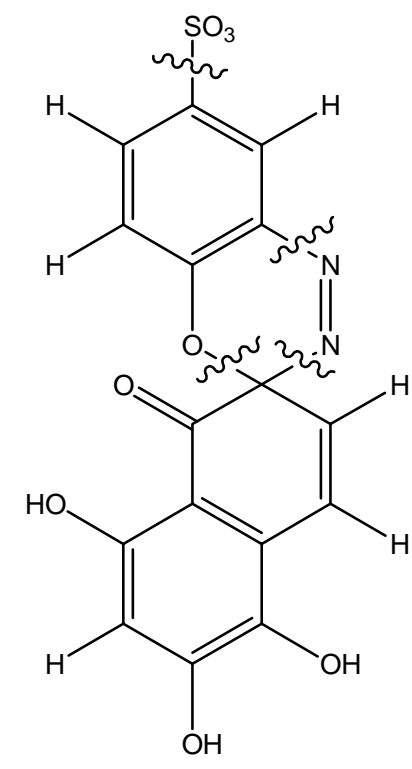

VI<smiles>O=CC=CC=C1C=CC=CC1=O</smiles>

VII
FIGURE 2 Structures of possible transformation products, MSMS fragmentation pattern is indicated in VI. 


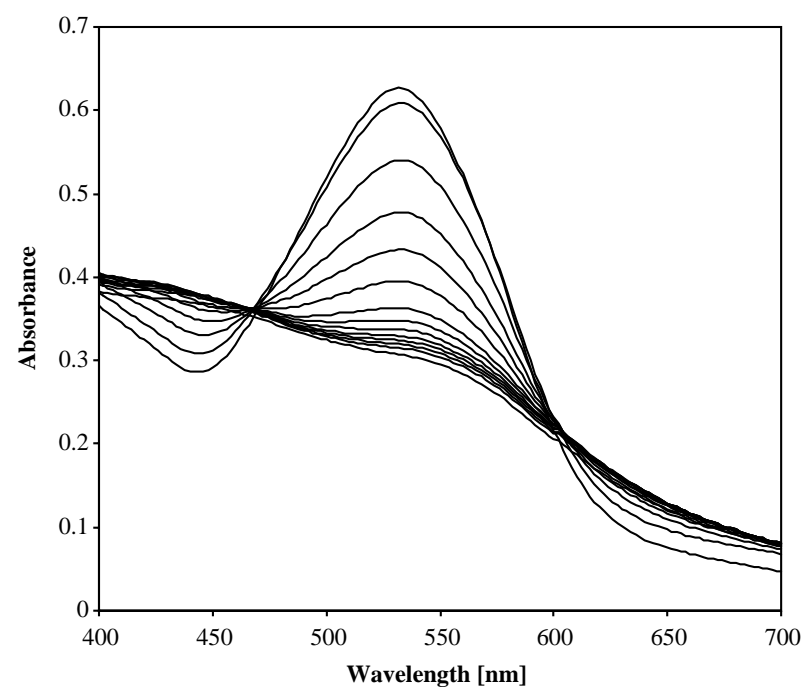

FIGURE 3 Time course of vis-spectra for the laccase-catalyzed decolorization of Diamond Black PV 200.

the transformation product is relatively stable and first looses a sulfonate group before subsequently molecular nitrogen $\mathrm{N}_{2}$ is eliminated. The fragment with $280 \mathrm{~m} / \mathrm{z}$ furthermore looses water $(262 \mathrm{~m} / \mathrm{z})$ and both of the latter fragments split off a fragment with $91 \mathrm{~m} / \mathrm{z}$. Based on these findings, we propose for the transformation product at $R_{\mathrm{t}} 5.70$ the structure given in Fig. 2 (VI).

The mass spectrum of the compound at $R_{\mathrm{t}} 6.32$ (of $468 \mathrm{~m} / \mathrm{z}$ ) showed that it contained no sulfonic acid group since no fragment of $80 \mathrm{~m} / z$ was split off. Since the molecular weight had nevertheless increased, we assume that it must be some recombination product from the radicals formed after laccasecatalyzed oxidation.

The secondary mass spectrum of the compound eluting after $6.53(=452 \mathrm{~m} / \mathrm{z})$ showed a very similar fragmentation pattern to the compound with $388 \mathrm{~m} / \mathrm{z}$. Again, loss of molecular nitrogen and sulfonate is found but in the reverse order, indicating that the heterocyclic ring is less stable than in the former case. It is also formed to a much lower extent as indicated by the much lower signal from the HPLC chromatogram. Here again, a mass fragment with of $91 \mathrm{~m} / z$ is split off and the elimination of water. Although no definite structure can be given, its structure must be closely related to that shown in Fig. 2 (VI).

Mass spectral analysis of the components with higher retention times $\left(R_{\mathrm{t}}=7.23,7.26\right.$, and 7.50) showed an increase in molecular weight upon laccase action with the largest fragments found at 715,717 , and $726 \mathrm{~m} / z$, respectively. The secondary mass spectra focused on 715 and $717 \mathrm{~m} / \mathrm{z}$, respectively, yielded again fragmentation patterns similar to the compound found with $388 \mathrm{~m} / \mathrm{z}$. After splitting off sulfonate and molecular nitrogen, a mass fragment of $109 \mathrm{~m} / \mathrm{z}$ left the molecules, which can be assigned to a hydroxylated derivative of the phenoxy fragment with $91 \mathrm{~m} / \mathrm{z}$ (see Fig. 2, VII). The compounds both contain another sulfonate group and both loose also a non-hydroxylated phenoxy fragment $(91 \mathrm{~m} / \mathrm{z})$. However, the complete elucidation of the structures for these higher molecular weight compounds was not possible. They were present only in minor quantities $(<2 \%)$.

\section{Kinetics of transformation of Diamond Black PV 200}

Subsequent kinetic studies for the determination of $\mathrm{pH}$ and dye concentration effects were performed using a chromatographically purified preparation of (IV). The chromatographic purification was done since the acetylated derivative, found in the commercial preparation, is not susceptible to laccase attack.

Kinetic analysis of Diamond Black PV (IV) transformation was based on the analysis of the decreasing peak area for the dye at $R_{\mathrm{t}}=5.4 \mathrm{~min}$. Plots of the initial rates vs. initial dye concentrations for different $\mathrm{pH}$-values are shown in Fig. 4. The continuous line was calculated from the non-linear curve fit based on Michaelis-Menten-like kinetics (taking into account substrate inhibition) and approximates the measured data points quite well. The corresponding apparent constants $K_{\mathrm{M}}^{\mathrm{app}}, V_{\max }^{\mathrm{app}}$ and $K_{\mathrm{I}}^{\mathrm{app}}$ are presented in Table II. $K_{\mathrm{M}}^{\mathrm{app}}$ and $V_{\max }^{\mathrm{app}}$ were used to calculate specifity constants $k_{\text {cat, dye, which are de- }}$ picted in Fig. 5 in dependence of the $\mathrm{pH}$.

Highest reaction rates with Diamond Black PV (IV) were achieved at $\mathrm{pH} 5$. At this $\mathrm{pH}$, also the most pronounced inhibition effects were found. The transformation of (IV) shows an optimum for the

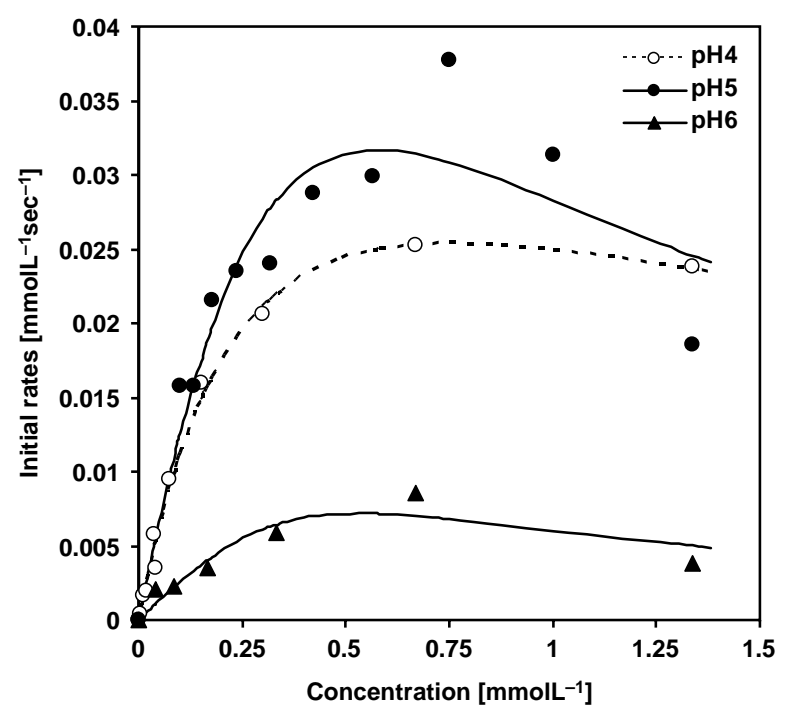

FIGURE 4 Kinetic profiles: Initial rates vs. dye concentration for the laccase catalysed oxidation of Diamond Black PV 200 at various $\mathrm{pH}$-values. 
TABLE II Results of the kinetic analysis

\begin{tabular}{lccccccc}
\hline Dye & $M_{\mathrm{W}}\left(\mathrm{g} \mathrm{mol}^{-1}\right)$ & $R_{\mathrm{t}}(\min )$ & $\lambda_{\max }(\mathrm{nm})$ & $V_{\max }^{\mathrm{app}}$ & $K_{\mathrm{M}}^{\text {app }}$ & $K_{\mathrm{I}}^{\text {app }}$ & $k_{\text {cat, dye }}$ \\
\hline Diamond Black PV 200 & 382.27 & 5.4 & 531 & 2.20 & 18.72 & $1.70 \times 10^{-2}$ & $1.18 \times 10^{-1}$ \\
3-Sulfophenyl-azo-dye & 366.28 & 5.9 & 539 & 0.46 & 942.87 & $3.00 \times 10^{-5}$ & $4.86 \times 10^{-4}$ \\
4-Sulfophenyl-azo-dye & 366.28 & 5.9 & 551 & 0.35 & 277.91 & $2.00 \times 10^{-5}$ & $1.24 \times 10^{-3}$ \\
Naphthyl-azo-dye & 417.34 & 8.4 & 570 & 0.15 & 595.84 & $2.00 \times 10^{-5}$ & $2.58 \times 10^{-4}$ \\
Nitro-substituted azo-dye & 411.26 & 5.2 & 559 & 3.05 & 150.45 & $1.14 \times 10^{-3}$ & $2.02 \times 10^{-2}$ \\
\hline
\end{tabular}

$M_{\mathrm{W}}$, dye molecular weight; $R_{\mathrm{t}}$, retention time; $\lambda_{\max }$, wavelength of maximum absorbance; $K_{\mathrm{M}}^{\mathrm{app}}, V_{\max }^{\mathrm{app}}, K_{\mathrm{I}}^{\mathrm{app}}$, apparent kinetic parameter calculated from nonlinear curve fitting using the equation $r_{\mathrm{i}}=\left(V_{\max }^{\mathrm{app}} \cdot \mathrm{c}\right) /\left(K_{\mathrm{M}}^{\mathrm{app}}+c_{\mathrm{d}}+c_{\mathrm{d}}^{2} / K_{\mathrm{I}}^{\text {app }}\right)$, where $r_{\mathrm{i}}$ and $c_{\mathrm{d}}$ mean the initial rates and dye concentrations, respectively; $k_{\text {cat, dye, }}$ specificity constant towards the dye, as determined from the ratio $V_{\max }^{\mathrm{app}} / K_{\mathrm{M}}^{\mathrm{app}}$.

specificity constants at $\mathrm{pH} 4$. Enzyme activity drops very rapidly when the $\mathrm{pH}$ is increasing towards $\mathrm{pH} 7$.

\section{Substrate Specificity of Laccase}

The substrate specificity of Trametes modesta laccase towards azo-dyes was further studied using the transformation of structurally closely related compounds based on IV. Similar to (IV), kinetic studies of the model dyes (I, II, III, and V) were based on the analysis of decreasing peak areas for the various eluted dyes as revealed from HPLC separation. All dyes were freshly synthesized and used after recrystallization. The UV/Vis spectral time courses during decolorization of the model azo-dyes were similar to the DBPV spectrum (data not shown). The modification of the basic structure lead to shifts of the absorbance maxima towards longer wavelengths (see Table II).

The $\mathrm{pH}$ optima for decolorization were also similar to the optimum found for (IV) between $\mathrm{pH} 4$ and 5. However, reactivities were generally much less. No enzymatic transformation at all was observed for dyes (II) and (III) at $\mathrm{pHs}<4$ and $>6$. The oxidation rates of the various model azo-dyes decreased in the order Diamond Black

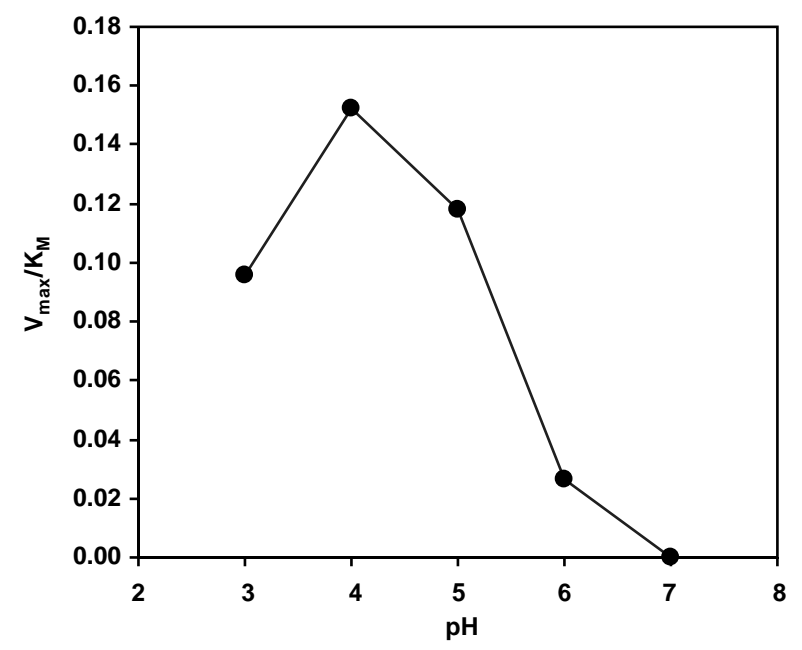

FIGURE 5 The $\mathrm{pH}$ dependence of the specificity constant, $k_{\text {cat, dye }}\left(V_{\max } / K_{\mathrm{M}}\right)$ for the laccase-catalyzed oxidation of Diamond Black PV 200.
PV 200 (IV) > 1,5-dihydroxy-2-(2'-hydroxy-3'-nitro)phenylazo-5'-sulfonic acid $(\mathbf{V})>1,5$-dihydroxy2-phenylazo-4'-sulfonic acid (I) $>1$,5-dihydroxy-2phenylazo-3'-sulfonic acid (II) $\approx 1,5$-dihydroxy-2naphtylazo-3'-sulfonic acid (III). All dyes showed inhibition effects with increasing initial dye concentrations. In Table II, the apparent kinetic constants are presented as calculated from a linear curve fit based on Michaelis-Menten-like kinetics with substrate inhibition. The corresponding specificity constants, $k_{\text {cat, dye, }}$ are also shown.

The nitro-substituted dye (V) was transformed at much lower rates as compared to (IV). Derivatives lacking a ortho-hydroxy group were much less susceptible towards laccase action. The position of sulfonate substituents in the phenyl ring had a minor effect on the biodegradability.

\section{DISCUSSION}

\section{Diamond Black PV 200 Transformation}

HPLC/MS analysis showed that the laccase-catalyzed transformation of IV produced very complex mixtures of different reaction products. As one of the main products, a compound of higher molecular weight than the original dye was found. Secondary mass spectroscopy revealed structural fragments that could possibly be explained by the structure VI shown in Fig. 2. Among the main transformation products, the oxidized cleavage product sulfobenzene-3,4-dichinone VII was found (Fig. 2). The corresponding hydroxynaphthalines or naphthochinoid low-molecular weight compounds were not detected as the complementary fragments of the azodye since but are likely to have undergone further oligomerization. This was suggested by compounds with increased molecular weight which were found in the MS-MS of minor reaction products with higher retention times $\left(R_{\mathrm{t}}>6 \mathrm{~min}\right)$. Since they lacked the sulfonate fragmentation pattern and it is unlikely that laccase induced any desulfonation, it is concluded that mixed recombination reactions are not favorable. Although the cleavage of aromatic rings has been reported to take place upon laccase action (Claus et al., 2002; Duran and Esposito, 2000), we did 
not find any indication for such processes with Diamond Black PV.

Laccases initially generate reactive radical species which subsequently undergo further oxidation either to cleavage or oligomerization products. It is therefore unlikely that all products found are direct oxidation products of laccase. According to Chivukula and Renganathan (1995), the mechanism of laccase mediated azo-dye decomposition proceeds first via two sequential electron abstractions. This is followed by an attack of the nucleophile water on the resulting resonance stabilized cation. Subsequently, breakdown of the dye molecule takes place concomitantly with the release of one proton and one molecule of $\mathrm{N}_{2}$ yielding chinoid aromatics and transient hydroperoxides, respectively (Chivukula and Renganathan, 1995). The resulting chinones and radicals could undergo coupling reactions yielding oligomeric and polymeric structures. The main function of the laccase-catalyst thus consists of oxidatively rendering the azo-dye more susceptible to further nucleophilic attack and nitrogen is eliminated in molecular form.

By choosing appropriate reaction conditions it should also be possible to shift the chemical equilibria between the enzymatically activated radical species towards oligomerization reactions. Polymerization reactions using laccases have been described earlier (e.g. Aktas et al., 2001; Osiadacz et al., 1999). This type of reaction could be advantageously used in laccase-catalyzed polymerization and precipitation of waste dyestuff.

\section{Substrate Specificity}

In order to study the influence of dye structure on biodegradability, structurally related model azodyes were synthesized. As the basic structure, the acid dye Diamond Black PV 200 (CI Mordant Black 9 , IV) was used since it is a very important industrial dye. The $\mathrm{pH}$ optimum did not change significantly when the substitution pattern of the basic structure IV was varied, staying between $\mathrm{pH} 4$ and 5 . Biodegradability, however, in terms of the rate of laccase-catalyzed dye transformation was strongly dependent on the structure of the dyes $(\mathbf{I V}>\mathbf{V}>$ II $>$ III $\approx$ I). In the series of the 3'-sulfophenyl-azodyes III, IV, and V, the introduction of a hydroxygroup (IV) enhanced the affinity of the enzyme for the substrate by a factor of approx. 240. The nitrogroup present in $\mathbf{V}$ diminished the susceptibility towards oxidation, however, $k_{\text {cat, dye }}$ for $\mathbf{V}$ was still more than 40 times greater than $k_{\text {cat, dye }}$ for III. Extending the $\pi$-electron system of III by ring annelation (I) did not result in any significant improvement in reaction rates. However, if the 3'sulfogroup (meta, III) is shifted to the $4^{\prime}$-position (para, II), the affinity of the enzyme for the dye may be increased threefold. Although an effect of the position of the sulfonate-group was observed, the presence or absence of hydroxy groups in the orthoposition to the azo-link predominantly governs biodegradation behaviour.

In an earlier study with designed model azo-dyes based on the azo-coupling of 1,5-dihydroxy-2-(2'hydroxy)-phenylazo-5'-sulfonic acid with differently substituted anilines (Kandelbauer et al ., 2004), it was found that their common structural feature was not a preferred laccase substrate. Their low overall reactivity with laccase made it difficult to obtain accurate quantitative results. Although each of the dyes contained a hydroxyl group on the naphthyl ring in the ortho-position to the azo-linkage, the rates for the most reactive derivatives, the ones substituted with another ortho-hydroxy group in the phenylring, were still about $10^{5}$ times slower than that for oxidation of IV. The nitro-substituted dyes were not accepted by the laccase and no decolorization took place at all. The reason for this low overall reactivity of our previous set of model azo-dyes could possibly have been the presence of two sulfonate groups on the naphthyl ring of the coupling component, both of them in meta-positions relative to the azo-bond. Sulfonate groups exhibit a strong electron withdrawing effect and might have been detrimental to the redox properties required by the enzyme. The varying substitution pattern on the phenyl ring could not compensate for the low reactivity probably resulting from the presence of the sulfonic acid groups.

In a different study we found that the same set of model azo-dyes was readily degraded by a reductive enzyme system, a newly isolated azo-reductase from the alkali and thermostable Bacillus sp. strain SF (Maier et al., 2004). Obviously, reducing the electron density at the azo-bond, which is deleterious for the laccase-catalyzed process, renders the molecule more susceptible towards enzymatic reduction.

The dihydroxy naphthyl core used for the model dyes in the present study may have conferred sufficient electron density to the molecules so that even those unsubstituted in the phenyl ring were still oxidized by laccase, albeit at very low rates. This made it possible with the present set of dyes to determine and compare specificity constants for differently substituted phenylazo compounds.

In the early mechanistic study by Chivukula and Renganathan (1995), effects of the substitution pattern of azo-dyes on their biodegradability were also examined in terms of reaction rates. All their model dyes carried a sulfo-group for solubility and a hydroxy group conferring the character of a laccase substrate, both, in the para-positions of the respective phenylrings. They systematically varied the 
substitution pattern introducing methyl, methoxy, chloro, and nitro groups. Among the dyes tested, only those with electron-rich methyl or methoxy substituents were oxidized. Unsubstituted 4-(4'-sulfophenylazo)-phenol and its 2-chloro and 2-nitro analogs were not oxidized. Obviously, one hydroxygroup in the para-position to the azo-bond in the otherwise unsubstituted dye was not sufficient to facilitate its oxidation. Azo-dyes sulfonated in the meta-position or carrying a hydroxy-group in the ortho-position to the azo-bond were not taken into consideration.

Since then, to our knowledge little further information regarding the structural requirements for laccase oxidation has appeared in the literature. In the majority of studies, whole cell systems were used for decolorization of commercial (e.g. Moreira et al ., 2000; Rodriguez et al., 1999; Kim et al., 1995; Fu and Viraraghavan, 2001 and references herein) or designed dyes (e.g. Martins et al., 2003, 2001; Spadaro et al., 1992) which complicates causal interpretation of dye structural effects. Other studies published more specifically on laccase-catalyzed decolorizations were restricted to different commercially available dyes (e.g. Peralta-Zamora et al., 2003; Abadulla et al., 2000; Reyes et al., 1999) and demonstrate well the wide applicability of laccases for dye remediation in general. However, due to the non-systematic choice of dyestuff, they are of limited use for deducing structure-reactivity relationships.

Martins et al. (2001) reported earlier a positional effect of sulfo-groups also using a set of structurally closely related model azo-dyes. In their study, 4'-hydroxy-3'-methoxyphenylazobenzene-4-sulfonic acid, carrying the sulfonic acid group in the paraposition to the azo-link was decolorized to a greater extent $(89 \%)$ than its meta-substituted analogue, 4'-hydroxy-3'-methoxyphenylazobenzene-3-sulfonic acid (83\%). However, the opposite result was found when an additional methoxy-group was present in the 5'-position. Unfortunately, only the overall decolorization during incubation with the growing fungus was assayed and no kinetic data were collected that could directly be linked to enzymatic specificities. Since the authors gave no indication of the enzymes involved in their model dye transformation, their findings are difficult to relate to our present study.

In a study of Soares et al. (2002), four synthetic model dyes of the diazo type were tested towards decolorization by a purified laccase from Aspergillus niger with and without redox mediators. Only one dye contained a sulfonic acid group and was readily transformed by the laccase. The three other dyes were insoluble and therefore, not decolorized by the free laccase in solution. According to the authors the enzyme was inhibited by the presence of ethanol which was used for dye solubilisation. No structural effects can be deduced from their set of model dyes.

\section{CONCLUSION}

The laccase oxidative transformation of dyes depends on their chemical structure. The presence of ortho-hydroxy groups with respect to the azolink was found to enhance the decolorization rates of azo-dyes with laccase whereas nitro groups stabilized the dye molecules against laccase action. The biotransformation of Diamond Black PV 200, the dye most susceptible to laccase, yielded both, cleavage and oligomerization products. Unlike mixed microbial cultures, laccases are not able to mineralize dyes but produce complex mixture of different reaction products. Although enzyme remediation of dyestuff successfully removes its color, a potentially harmful organic load may remain in the process waters. Thus, an interesting future perspective in the application of laccases for the treatment of waste dyestuffcontaining process waters is the polymerization of phenolic dye fragments rather than their oxidative breakdown. If such polymerized fragments were of sufficiently increased molecular weight they could readily be removed by a subsequent filtration step (laccase assisted dye precipitation). Consequently, future research activities should focus on optimization of the reaction conditions in order to achieve maximum oxidative coupling of primarily formed dye fragments. Together with introduction of substitutents which enhance laccase catalysed decolorization this could lead to the design of novel "biodegradible" dyes.

\section{References}

Abadulla, E., Tzanov, T., Costa, S., Robra, K.H., Cavaco-Paulo, A. and Gübitz, G.M. (2000) Decolorization and detoxification of textile dyes with a laccase from Trametes hirsuta, Appl. Environ. Microbiol. 66, 3357-3362.

Aktas, N., Cicek, H., Ünal, A.T., Kibarer, G., Kolankaya, N. and Tanyolac, A. (2001) Reaction kinetics for laccase-catalyzed polymerization of 1-naphthol, Biores. Technol. 80, 29-36.

Bajpai, P., Mehna, A. and Bajpai, P.K. (1993) Decolorization of kraft bleach plant effluent with the white-rot fungus Trametes versicolor, Process Biochemistry 28, 377-384.

Bechtold, T., Burtscher, E. and Turcanu, A. (2001) Cathodic decolourisation of textile waste water containing reactive dyes using a multi-cathde electrolyser, J. Chem. Technol. Biotechnol. 76, 303-311.

Binkley, J. and Kandelbauer, A. (2003) Effluent treatment enzymes in activated sludge, In: Cavaco-Paulo, A. and Gübitz, G.M., eds, Textile processing with enzymes (Woodhead Publishing, Cambridge), pp. 199-221.

Bollag, J.M., Shuttleworth, K.L. and Anderson, D.H. (1988) Laccase-mediated detoxication of phenolic compounds, Appl. Environ. Microbiol. 54, 3086-3091.

Campos, R., Kandelbauer, A., Robra, K.H., Cavaco-Paulo, A. and Gübitz, G.M. (2001) Indigo degradation with purified laccases from Trametes hirsuta and Sclerotium rolfsii, J. Biotechnol. 89, $131-139$. 
Cavaco-Paulo, A. and Gübitz, G.M. (2004) Textile processing with enzymes (Woodhead Publishing, Cambridge).

Chivukula, M. and Renganathan, V. (1995) Phenolic azo dye oxidation by laccase from Pyricularia oryzae, Appl. Environ. Microbiol. 61, 4374-4377.

Claus, H. (2004) Laccases: structure, reactions, distribution, Micron 35, 93-96.

Claus, H., Faber, G. and König, H. (2002) Redox-mediated decolorization of synthetic dyes by fungal laccases, Appl. Microbiol. Biotechnol. 59, 672-678.

D'Annibale, A., Stazi, S.R., Vinciguerra, V., Di Mattia, E. and Sermanni, G.G. (1999) Characterization of immobilized laccase from Lentinula edodes and its use in olive-mill wastewater treatment, Process Biochemistry 34, 697-706.

Duran, N. and Esposito, E. (2000) Potential applications of oxidative enzymes and phenoloxidase-like compounds in wastewater and soil treatment, Appl. Catal. B: Environ. 28, 83-99.

Fu, Y. and Viraraghavan, T. (2001) Fungal decolorization of dye wastewaters: a review, Biores. Technol. 79, 251-262.

Guebitz, G.M., Steiner, W. and Cavaco-Paulo, A. (2004) Editorial: Enzymes in fibre processing, Biocatalysis and biotransformation 22, 297.

Kandelbauer, A., Schnitzhofer, W., Kessler, R.W., Cavaco-Paulo, A. and Gübitz, G.M. (2003) Production of a laccase from the white-rot fungus Trametes modesta for application in the decolorization of textile dyes, In: Hardin, I.R., Akin, D.E. and Wilson, S.J., eds, Advances in biotechnology for textile processing (University of Georgia, Athens), pp. 1-15.

Kandelbauer, A. and Gübitz, G.M. (in press) Bioremediation for the decolorization of textile dyes: a review. In: Lichtfouse, E. and Schwarzbauer, J. (Eds.), Environmental Chemistry. Springer, New York.

Kandelbauer, A., Maute, O., Kessler, R.W., Erlacher, A. and Gübitz, G.M. (2004) Study of dye decolorization in an immobilized laccase enzyme-reactor using online spectroscopy, Biotechnol. Bioeng. 87, 552- 563 .

Kapdan, I.K. and Kargi, F. (2002) Biological decolorization of textile dyestuff containing wastewater by Coriolus versicolor in a rotating biological contactor, Enzyme Microb. Technol. 30, 195- 199.

Kim, S.J., Ishikawa, K., Hirai, M. and Shoda, M. (1995) Characteristics of a newly isolated fungus, Geotrichum candidum Dec 1, which decolorizes various dyes, J. Ferm. Bioeng. 79, 601-607.

Kirby, N., Marchant, R. and McMullan, G. (2000) Decolourisation of synthetic textile dyes by Phlebia tremellosa, FEMS Microbiol. Lett. 188, 93-96.

Maier, J., Kandelbauer, A., Erlacher, A., Cavaco-Paulo, A. and Gübitz, G.M. (2004) A new alkali-thermostable azoreductase from Bacillus sp. strain SF, Appl. Environ. Microbiol. 70, 837844 .

Majcherczyk, A., Johannes, C. and Hüttermann, A. (1998) Oxidation of polycyclic aromatic hydrocarbons (PAH) by laccase of Trametes versicolor, Enzyme Microb. Technol. 22, 335-341.

Martins, M.A.M., Ferreira, I.C., Santos, I.M., Queiroz, M.J. and Lima, N. (2001) Biodegradation of bioaccessible textile azo dyes by Phanerochaete chrysosporium, J. Biotechnol. 89, 91-98.

Martins, M.A.M., Lima, N., Silvestre, A.J.D. and Queiroz, M.J. (2003) Comparative studies of fungal degradation of single or mixed bioaccessible reactive azo dyes, Chemosphere 52, $967-$ 973.

McMullan, G., Meehan, C., Conneely, A., Kirby, N., Robinson, T., Nigam, P., Banat, I.M., Marchant, R. and Smyth, W.F. (2001) Microbial decolourisation and degradation of textile dyes, Appl. Microbiol. Biotechnol. 56, 81-87.

Moreira, M.T., Mielgo, I., Feijoo, G. and Lema, J.M. (2000) Evaluation of different fungal strains in the decolorization of synthetic dyes, Biotechnol. Lett. 22, 1499-1503.
Novotny, C., Rawal, B., Bhatt, M., Patel, M., Sasek, V. and Molitoris, H.P. (2001) Capacity of Irpex lacteus and Pleurotus osteatus for decolorization of chemically different dyes, $J$. Biotechnol. 89, 113- 122.

Nyanhongo, G.S., Gomes, J., Gübitz, G.M., Zvauya, R., Read, J. and Steiner, W. (2002) Decolorization of textile dyes by laccases from a newly isolated strain of Trametes modesta, Wat. Res. 36, 1449-1456.

Osiadacz, J., Al-Adhami, A.J.H., Bajraszewska, D., Fischer, P. and Peczynska-Czoch, W. (1999) On the use of Trametes versicolor laccase for the conversion of 4-methyl-3-hydroxyanthranilic acid to actinocin chromophore, J. Biotechnol. 72, 141-149.

Peralta-Zamora, P., Pereira, C.M., Tiburtius, E.R.L., Moraes, S.G., Rosa, M.A., Minussi, R.C. and Durán, N. (2003) Decolorization of reactive dyes by immobilized laccase, Appl. Catalysis B: Environ. 42, 131- 144 .

Pickard, M.A., Vandertol, H., Roman, R. and Vazquez-Duhalt, R. (1999) High production of ligninolytic enzymes from white rot fungi in cereal bran liquid medium, Can. J. Microbiol. 45, $627-631$.

Reyes, P., Pickard, M.A. and Vazquez-Duhalt, R. (1999) Hydroxybenzotriazole increases the range of textile dyes decolorized by immobilized laccase, Biotechnol. Lett. 21, 875-880.

Robinson, T., McMullan, G., Marchant, R. and Nigam, P. (2001) Remediation of dyes in textile effluent: a critical review on current treatment technologies with a proposed alternative, Biores. Technol. 77, 247-255.

Rodriguez, E., Pickard, M.A. and Vazquez-Duhalt, R. (1999) Industrial dye decolorization by laccases from ligninolytic fungi, Curr. Microbiol. 38, 27-32.

Schliephake, K., Mainwaring, D.E., Lonergan, G.T., Jones, I.K. and Baker, W.L. (2000) Transformation and degradation of the disazo dye Chicago Sky Blue by a purified laccase from Pycnoporus cinnabarinus, Enzyme Microb. Technol. 27, 100107.

Slokar, Y.M. and Le Marechal, A.M. (1998) Methods of decolorization of textile wastewaters, Dyes and Pigments 37, 335- 356.

Soares, G.M.B., Amorim, M.T.P., Hrdina, R. and Costa-Ferreira, M. (2002) Studies on biotransformation of novel disazo dyes by laccase, Process Biochemistry 37, 581-587.

Spadaro, J.T., Gold, M.H. and Renganathan, V. (1992) Degradation of azo dyes by the lignin degrading fungus Phanerochaete chrysosporium, Appl. Environ. Microbiol. 58, 2397-2401.

Stolz, A. (2001) Basic and applied aspects in the microbial degradation of azo dyes, Appl. Microbiol. Biotechnol. 56, 6980.

Sumathi, S. and Manju, B.S. (2000) Uptake of reactive textile dyes by Aspergillus foetidus, Enz. Microb. Technol. 27, 347-355.

Suzuki, T., Timofei, S., Kurunczi, L., Dietze, U. and Schüürmann, G. (2001) Correlation of aerobic biodegradability of sulfonated azodyes with chemical structure, Chemosphere 45, 1-9.

Thurston, C.F. (1994) The structure and function of fungal laccases, Microbiol. 140, 19-26.

Wesenberg, D., Kyriakides, I. and Agathos, S.N. (2003) White-rot fungi and their enzymes for the treatment of industrial dye effluents, Biotechnol. Advances 22, 161-187.

Wong, Y. and Yu, J. (1999) Laccase-catalyzed decolorization of synthetic dyes, Wat. Res. 33, 3512-3520.

Xu, F. (1996) Oxidation of phenols, anilines, and benzenethiols by fungal laccases: correlation between activity and redox potentials as well as halide inhibition, Biochem. 35, 76087614.

Xu, F., Kulys, J.J., Duke, K., Li, K., Krikstopaitis, K., Deussen, H.J., Abbate, E., Galinyte, V. and Schneider, P. (2000) Redox chemistry in laccase-catalyzed oxidation of $N$-hydroxy compounds, Appl. Environ. Microbiol. 66, 2052-2056. 